\title{
BIOMASSA AÉREA E PRODUÇÃO PRIMÁRIA DO ESTRATO HERBÁCEO EM CAMPO DE ELYONURUS MUTICUS SUBMETIDO À QUEIMA ANUAL, NO PANTANAL ${ }^{1}$
}

\author{
EVALDO LUIS CARDOSO², SANDRA MARA ARAÚJO CRISPIM², \\ CRISTINA APARECIDA G. RODRIGUES ${ }^{3}$ eWALDOMIRO BARIONI JÚNIOR ${ }^{4}$
}

\begin{abstract}
RESUMO - O trabalho foi conduzido no Pantanal, em fitofisionomia de campo a savana, regionalmente denominada de caronal, pela dominância de Elyonurus muticus. Os objetivos foram avaliar o efeito da queima anual de caronal sobre a biomassa aérea acumulada, produção primária líquida da parte aérea (PPLA) do estrato herbáceo e cobertura do solo. Foram coletados dados mensais de biomassa aérea acumulada durante dois anos, em uma área com queima em set./95 e ago./96, e outra sem queima. A PPLA foi estimada através das diferenças de biomassa aérea viva coletada mensalmente. A queima reduziu a biomassa aérea acumulada em aproximadamente $36 \%$ no primeiro ano e $50 \%$ no segundo. Houve uma tendência de redução de biomassa acumulada com a repetição da queima. A PPLA do estrato herbáceo nas áreas sem queima e com queima foi $3.850 \mathrm{~kg} / \mathrm{ha}$ e $4.980 \mathrm{~kg} / \mathrm{ha}$ no primeiro ano, e $5.090 \mathrm{~kg} / \mathrm{ha}$ e $2.880 \mathrm{~kg} / \mathrm{ha}$ no segundo, respectivamente. A cobertura do solo 30 dias após a queima foi de aproximadamente $30 \%$, e somente quatro a seis meses depois foi restabelecido o porcentual da área sem queima
\end{abstract}

Termos para indexação: Axonopus purpusii, cobertura do solo, Mesosetum chaseae, pastagens nativas, ecologia.

AERIAL BIOMASS AND PRIMARY PRODUCTION OF HERBACEOUS COMMUNITIES IN A NATIVE
GRASSLAND OF ELYONURUS MUTICUS UNDER ANNUAL BURNINGS IN THE PANTANAL, BRAZIL

ABSTRACT - This work was conducted in a native grassland of the Pantanal, locally called "caronal" due to the dominance of Elyonurus muticus. The objectives were to evaluate the effect of annual burnings of "caronal" on the cumulative aerial biomass, aboveground net primary production (ANPP) of herbaceous communities and soil cover. Monthly data of cumulative aerial biomass were collected during two years in an area which was burned in September/95 and in August/96, and in another area which was free of burning. ANPP was estimated through differences between aerial live biomass gathered monthly. Annual burnings reduced cumulative aerial biomass about $36 \%$ in the first year and $50 \%$ in the second year. There was a tendency of reduction of cumulative aerial biomass with repetition of the burnings. The ANPP herbaceous communities in the areas free of burning and with burnings were $3,850 \mathrm{~kg} / \mathrm{ha}$ and 4,980 kg/ha, in the first year, and 5,090 kg/ha and 2,880 kg/ha in the second, respectively. Thirty days after burning, the soil cover was about $30 \%$ and only four to six months after burning it was re-established as the area free of burning.

Index terms: Axonopus purpusii, soil cover, Mesosetum chaseae, native grasslands, ecology.

${ }^{1}$ Aceito para publicação em 27 de julho de 1999.

Trabalho desenvolvido com apoio financeiro do Conselho Estadual de Ciência e Tecnologia (CECITEC), da Secretaria de Estado de Planejamento e de Ciência e Tecnologia (Seplan-MS).

${ }^{2}$ Eng. Agrôn., M.Sc., Embrapa-Centro de Pesquisa Agropecuária do Pantanal (CPAP), Caixa Postal 109,
CEP 79320-900 Corumbá, MS.

E-mail: evaldo@cpap.embrapa.br, scrispim@cpap.embrapa.br

${ }^{3}$ Zootecnista, M.Sc., Embrapa-CPAP.

E-mail: crisagr@cpap.embrapa.br

${ }^{4}$ Estatístico, M.Sc., Embrapa-Centro Nacional de Pesquisa de Suínos e Aves (CNPSA), Caixa Postal 21, CEP 89700-000

Concórdia, SC. E-mail: barioni@cnpsa.embrapa.br 


\section{INTRODUÇÃO}

A prática de queimar as savanas e os campos naturais durante a época de seca é bastante comum em muitas regiões tropicais e subtropicais. Entre as diversas razões apresentadas para justificar esta forma popular de manejo, destaca-se a necessidade de obtenção de forragem fresca e palatável para o gado, em períodos em que este tipo de alimento torna-se escasso (Coutinho et al., 1982). O fogo, atuando como elemento seletivo sobre a vegetação, propicia o aparecimento de uma flora indicadora, e estimula a rápida formação de brotos verdes, independentemente das chuvas, em razão do seu efeito de poda sobre estas plantas, que utilizam reservas armazenadas no sistema radicular (Coutinho, 1976).

No Pantanal, as pastagens nativas constituem a alimentação básica dos bovinos, e estão sujeitas a flutuação quantitativa e qualitativa, em razão das características ecológicas da região, podendo ocorrer dois períodos críticos na disponibilidade de matéria seca: um, de meados ao fim do período chuvoso, e outro, de meados ao fim da seca (Pott et al., 1989). A queima é realizada anualmente, como alternativa para aumentar a oferta de forragens no período seco; contudo, sua utilização se faz de forma seletiva e localizada, procurando-se eliminar ou conter a expansão de espécies indesejáveis e promover o rebrote das forrageiras de baixa aceitabilidade, sendo comumente queimadas as áreas de caronal (Elyonurus muticus), de capim-fura-bucho (Paspalum carinatum e P. lineare), de capim-rabode-burro (Andropogon bicornis) e cerrados ralos (Pott, 1982). A rebrota promovida pelo fogo parece essencial ao aproveitamento das forrageiras de baixa aceitabilidade, embora, talvez, $90 \%$ da fitomassa aérea seja perdida pela queima (Pott, 1982).

O caronal recobre grandes áreas no Pantanal, especialmente nas sub-regiões da Nhecolândia e dos Paiaguás. Esta fitofisionomia de campo a savana, geralmente pouco ou não alagável, tem como componente principal o capim-carona (Elyonurus muticus), gramínea grosseira e de baixa aceitabilidade, cuja rebrota pós-fogo é pastejada na seca, e possui, ainda, entre suas touceiras, forrageiras nativas de melhor qualidade, que são aproveitadas na cheia (Comastri Filho, 1984; Pott, 1988).

Pesq. agropec. bras., Brasília, v.35, n.8, p.1501-1507, ago. 2000
O estudo da produção primária é fundamental para o conhecimento da estrutura trófica de uma comunidade, pois a energia armazenada pela fotossíntese é, posteriormente, utilizada por todos os componentes do ecossistema (Meirelles, 1981). Segundo Wiegert \& Evans (1964), a quantificação da taxa de energia que é fixada pela vegetação é o ponto de partida para o entendimento do fluxo de energia no ecossistema. Vários trabalhos que estudaram o efeito do fogo relatam um aumento da produção primária após a queima, atribuído, em parte, à retirada da camada de litter e da cobertura vegetal viva que impedia a insolação do solo; no entanto, isto varia conforme a época e frequiência da queimada, tipo de solo e clima da região (Batmanian, 1983). Embora a queima seja considerada instrumento de manejo das pastagens nativas e uma prática comumente empregada, constatase, no entanto, que ainda são inexistentes as informações fundamentadas em trabalhos científicos que elucidem os seus efeitos no Pantanal.

Este trabalho teve por objetivo avaliar o efeito da queima anual de um campo de caronal sobre a biomassa aérea acumulada, produção primária líquida da parte aérea do estrato herbáceo e cobertura do solo.

\section{MATERIAL E MÉTODOS}

O experimento foi conduzido na fazenda Nhumirim, campo experimental da Embrapa-Centro de Pesquisa Agropecuária do Pantanal (CPAP), sub-região da Nhecolândia, localizada na latitude $18^{\circ} 59^{\prime} \mathrm{S}$ e longitude $56^{\circ} 37^{\prime} \mathrm{W}$, Pantanal Sul-Mato-Grossense, no período de setembro de 1995 a julho de 1997.

De acordo com a classificação climática de Köppen, o Pantanal possui clima tropical subúmido (Aw), com média em torno de $1.100 \mathrm{~mm}$ anuais de chuva, e há uma estação chuvosa de outubro a março e uma relativamente seca de abril a setembro; a temperatura média anual é de $26^{\circ} \mathrm{C}$; pode ocorrer geada esporádica (Cadavid García, 1984).

O estudo foi desenvolvido em uma área regionalmente denominada de caronal, livre de queimadas em anos anteriores, cuja caracterização, realizada por meio de 40 quadrados de $1 \mathrm{~m} \mathrm{x} 1 \mathrm{~m}$ lançados aleatoriamente, evidenciou as seguintes espécies, com sua respectiva frequiência absoluta (frequiência superior a 5\%): Elyonurus muticus (95\%), Mesosetum chaseae (95\%), Richardia grandiflora (55\%), Axonopus purpusii (50\%), Andropogon selloanus (35\%), Trachypogon sp. (30\%), Waltheria communis (20\%), 
Borreria verticillata (10\%), Desmodium barbatum (5\%), Hyptis crenata (6\%), Ruellia sp. (5\%) e Cyperus sp. (5\%). O relevo plano é o dominante, e o solo foi classificado como Areia Quartzosa Hidromórfica distrófica, com os seguintes resultados de análises químicas de amostras coletadas na camada de 0 a $20 \mathrm{~cm}$ : $\mathrm{pH}$ em água = 5,2; $\mathrm{P}=1 \mathrm{mg} \mathrm{dm}^{-3}$; cátions trocáveis em $\mathrm{mmol}_{\mathrm{c}} \mathrm{dm}^{-3}$ : $\mathrm{Ca}+\mathrm{Mg}=3,0 ; \mathrm{K}=0,95$ e $\mathrm{Al}=0$.

No campo de caronal, delimitaram-se duas áreas de $100 \mathrm{~m}$ x $40 \mathrm{~m}$, devidamente aceiradas e cercadas com fios de arame, para impedir a entrada de animais, correspondendo respectivamente, aos tratamentos-testemunha (sem queima - SQ) e com queima anual (CQ). Em cada área, foram demarcadas dez parcelas adjacentes de $20 \mathrm{~m} \times 20 \mathrm{~m}$, dentro das quais foram feitas as avaliações mensais.

Em setembro de 1995, logo após as primeiras chuvas, efetuou-se a queima de uma das áreas, e 30 dias após, iniciaram-se as coletas mensais de biomassa aérea acumulada e avaliação da cobertura do solo, realizadas durante os 11 meses subseqüentes. Em agosto de 1996, logo após as primeiras chuvas, efetuou-se novamente a queima da mesma área, e 30 dias após, iniciaram-se as avaliações mensais durante os 11 meses subsequientes.

A biomassa aérea acumulada foi determinada por meio do corte mensal de toda a vegetação herbácea presente em um quadrado de $1 \mathrm{~m} \times 1 \mathrm{~m}$, e foram realizadas dez amostragens por área, cada uma correspondendo a uma parcela. Em cada coleta utilizaram-se quadrados anteriormente não coletados. O material foi cortado rente ao solo, separando-se os seguintes componentes: Elyonurus muticus (espécie dominante), Axonopus purpusii e Mesosetum chaseae (espécies de interesse forrageiro), agrupamento de outras espécies (espécies de menor frequiência) e biomassa morta. O material coletado foi acondicionado em saco de papel e mantido em estufa por 48 horas a $65^{\circ} \mathrm{C}$, obtendo-se o peso da matéria seca.

A estimativa da produção primária líquida da parte aérea (PPLA) foi obtida pelo método da análise dos vários picos do material vivo descrito por Singh et al. (1975). O método consiste em diminuir o valor de biomassa viva de cada coleta pelo valor obtido na coleta anterior. Portanto, a PPLA foi obtida através do somatório dos incrementos positivos de biomassa aérea viva determinados entre duas coletas consecutivas.

A estimativa da cobertura de solo $(\%)$ foi realizada visualmente em quadrados de $1 \mathrm{~m} \mathrm{x} \mathrm{1m,} \mathrm{antes} \mathrm{do} \mathrm{corte} \mathrm{de}$ biomassa, e foram realizadas dez amostragens por área, cada uma correspondendo a uma parcela. Pelo fato de esta variável ser caracterizada por grande amplitude de variação, os dados foram transformados para a análise estatísti- ca em arco seno $\sqrt{\mathrm{p} / 100}$, visando à homogeneidade da variância. A discussão e conclusões são referentes aos dados originais.

O modelo de análise de variância levou em consideração os efeitos de tratamento e tempo (meses de coleta) com as respectivas interações. Para a comparação de médias de biomassa acumulada adotou-se o teste de Tukey a $5 \%$ de probabilidade. Utilizou-se o pacote estatístico SAS (SAS Institute, 1989) para as análises.

\section{RESULTADOS E DISCUSSÃO}

A queima concorreu para reduzir significativamente $(\mathrm{P}<0,05)$ a biomassa aérea total acumulada, sendo que no período subseqüente à primeira queima (out./95 a ago./96), a biomassa obtida na área com queima (CQ) foi, aproximadamente, $36 \%$ menor que à na área sem queima (SQ), e no período subseqüente à segunda queima (set./96 a jul./97), foi, aproximadamente, 50\% menor (Tabela 1). Resultados similares foram relatados em outros trabalhos (Corrêa \& Aronovich, 1979; Cesar, 1980; Batmanian, 1983; Neiva, 1990). A repetição da queima condicionou uma biomassa aérea total acumulada menor do que a obtida após a primeira queima, e intensificou ainda mais a diferença dos tratamentos SQ e CQ. Embora os dados disponíveis sejam relativos a somente dois anos, esta tendência desperta preocupação quanto à dinâmica dessa biomassa por longo período com incidência anual de queima, principalmente considerando-se a baixa fertilidade e textura arenosa dos solos que compõem esta fitofisionomia. Atualmente, é opinião compartilhada por vários autores que o fogo é fator de manutenção de ambientes como as savanas e o cerrado, impedindo sua evolução para floresta, acelerando, por exemplo, a erosão do solo e contribuindo para a perda gradual de sua fertilidade (Cavalcanti, 1978).

As médias de biomassa viva (BV) e biomassa morta (BM) acumulada foram significativamente $(\mathrm{P}<0,05)$ inferiores no tratamento $C Q$ nos dois períodos de avaliação, e a BM foi quase totalmente eliminada (Tabela 1). Certamente a elevada diferença constatada na média de BM dos dois tratamentos, devese também a um efeito residual do material proveniente do crescimento de anos anteriores e que se transformou em material morto, visto que a área não havia sido queimada em anos anteriores. Brâncio et al.

Pesq. agropec. bras., Brasília, v.35, n.8, p.1501-1507, ago. 2000 
(1997) sugerem que a maior disponibilidade de matéria seca em áreas sem queima é, em parte, explicada pelo efeito residual do material proveniente do crescimento em anos anteriores.

Considerando-se as condições climáticas da região, com baixa precipitação pluvial e altas temperaturas, e o fato de os solos possuírem teores de argila variando de $2 \%$ a $4 \%$ - portanto, composição granulométrica que condiciona rápida perda de água das chuvas -, a cobertura morta assume importante papel na manutenção da umidade em níveis satisfatórios. De acordo com De Bano \& Conrad (1978), a queima de restos vegetais e/ou temperaturas superficiais elevadas podem induzir perda da atração (ou polaridade) das partículas de solos arenosos, promovendo um decréscimo acentuado na capacidade de infiltração de água no solo. Kucera et al. (1967) relataram que, nas áreas mais secas, onde a temperatura do solo não é limitante e a umidade já está em níveis baixos, a passagem do fogo, com o conseqüente aumento da temperatura e diminuição da umidade, passaria a ser prejudicial para o crescimento das plantas, o mesmo efeito ocorreria em áreas em que logo após a queimada houvesse uma grande seca.

O comportamento mensal da BM e BV nas áreas SQ e CQ durante os dois períodos de avaliação é apresentado nas Figs. 1 e 2. O fogo promoveu uma remoção de quase toda a $\mathrm{BM}$ existente, e a presença de pequena $\mathrm{BM}$ foi constatada somente sete meses após a primeira e segunda queima. A BV no período subseqüente à primeira queima não apresentou diferença significativa entre as médias mensais das duas áreas. No entanto, o incremento mensal de matéria seca foi superior na área $C Q$, embora a tendência tenha sido semelhante nas duas áreas, ou seja, um acréscimo linear até o mês de junho e um decréscimo nos meses de julho e agosto, período de seca. Após a segunda queima, enquanto a área SQ sugeriu uma possível estabilização na produção de matéria seca, a área CQ apresentou durante os sete primeiros meses $\mathrm{BV}$ significativamente menor $(\mathrm{P}<0,05)$ que a área SQ. Segundo Castilhos \& Jacques (1984), na fase inicial após a queimada o crescimento das plantas é lento, em razão da redução do índice de área foliar. A mesma consideração foi feita por Corrêa \& Aronovich (1979), com capim Hyparrhenia rufa, constatando que em áreas queimadas o início de pastejo tinha que ser retardado, exatamente em virtude de seu lento crescimento inicial.

Neste estudo, avaliou-se, ainda, a biomassa aérea de duas espécies de interesse forrageiro, Axonopus purpusii e Mesosetum chaseae, as quais mostraram um comportamento diferenciado em relação à queima anual. A. purpusii apresentou uma rápida rebrotação nos meses subseqüentes à primeira queima (Fig. 3), com biomassa significativamente $(\mathrm{P}<0,05)$ superior à obtida na área $\mathrm{SQ}$; entretanto, após a segunda queima não foi constatada diferença significativa entre as duas áreas. A biomassa de M. chaseae após a primeira queima não apresentou diferença significativa entre as duas áreas, porém após a segunda queima foi significativamente $(\mathrm{P}<0,05)$ superior à obtida na área $\mathrm{SQ}$, refletida principalmente nos últimos seis meses (Fig. 4). Embora a queima em dois anos consecutivos tenha proporcionado,

TABELA 1. Valor médio de biomassa aérea acumulada no período subseqüente à primeira queima, outubro/95 a agosto/96 è̀ segunda queima, setembro/96 a julho/97, nos tratamentos sem queima (SQ) e com queima anual (CQ) em campo de Elyonurus muticus no Pantanal'.

\begin{tabular}{lcccc}
\hline Período de avaliação & Tratamento & Biomassa viva & $\begin{array}{c}\text { Biomassa morta } \\
\text { (MS, kg/ha) }\end{array}$ & Biomassa total \\
\hline Outubro/95 a agosto/96 & SQ & $3.357 \mathrm{~b}$ & $1.494 \mathrm{~b}$ & $4.851 \mathrm{~b}$ \\
Outubro/95 a agosto/96 & CQ & $3.033 \mathrm{c}$ & $75 \mathrm{c}$ & $3.108 \mathrm{c}$ \\
Setembro/96 a julho/97 & SQ & $3.871 \mathrm{a}$ & $1.759 \mathrm{a}$ & $5.630 \mathrm{a}$ \\
Setembro/96 a julho/97 & CQ & $2.696 \mathrm{~d}$ & $100 \mathrm{c}$ & $2.796 \mathrm{~d}$ \\
\hline
\end{tabular}

${ }^{1}$ Médias seguidas da mesma letra na coluna não diferem estatisticamente a 5\% de probabilidade pelo teste de Tukey. 
em pelo menos um ano, maior biomassa aérea nas duas espécies, possivelmente condicionada pelo bom aproveitamento dos nutrientes provenientes das cinzas e pela menor competição por água e luz, não se pode afirmar que estas espécies tenham este mesmo comportamento em uma condição de freqüência anual de queima durante vários anos. Para isto seria necessário mais tempo de estudo.

A produção primária no período subseqüente à primeira queima foi $4.980 \mathrm{~kg} / \mathrm{ha}$, e $3.850 \mathrm{~kg} / \mathrm{ha}$ nas áreas CQ e SQ, respectivamente. No período subseqüente à segunda queima, a produção primária foi $5.090 \mathrm{~kg} / \mathrm{ha}$, e $2.880 \mathrm{~kg} / \mathrm{ha}$ nas áreas CQ e SQ, res-

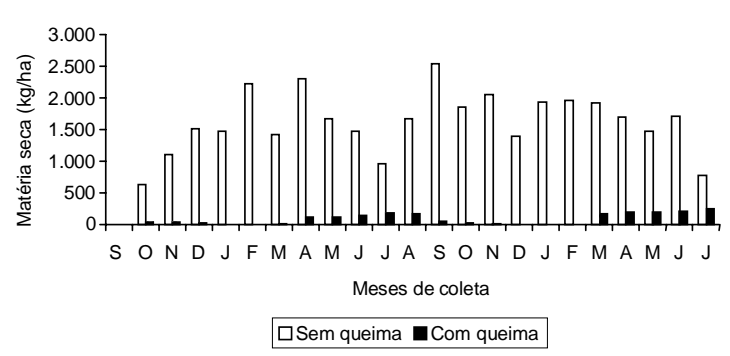

FIG. 1. Variação mensal de biomassa morta nos tratamentos sem queima (SQ) e com queima anual (CQ) em setembro/95 e em agosto/96, em campo de Elyonurus muticus no Pantanal, no período de outubro/95 a julho/97.

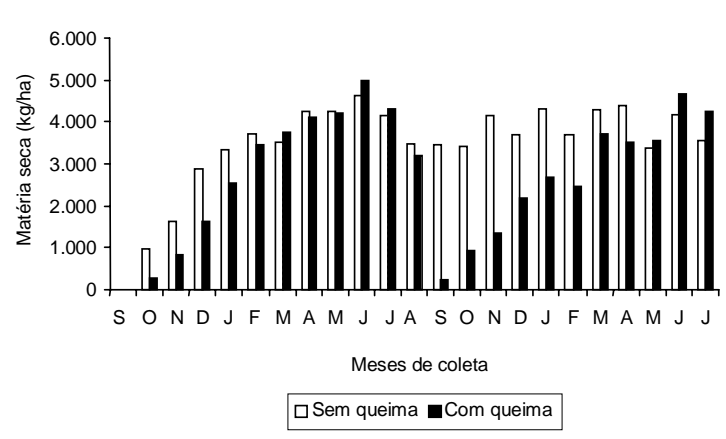

FIG. 2. Variação mensal de biomassa viva nos tratamentos sem queima (SQ) e com queima anual (CQ) em setembro/95 e em agosto/96, em campo de Elyonurus muticus no Pantanal, no período de outubro/95 a julho/97. pectivamente. Portanto, a queima concorreu para aumentar a produção primária. Embora o método considerado seja passível de utilização, Meirelles (1981) ressalta que os valores obtidos são uma subestimação da produção real, pois não se considera o que foi respirado pelas plantas, consumido por herbívoros e transformado em material morto. Contudo, esses resultados estão de acordo com os relatados por vários autores que estudaram o efeito do fogo sobre a produção primária, tanto na região tropical (Blydenstein,1963; San José \& Medina, 1975; Amissah et al., 1980; Meirelles, 1981), como na tem-

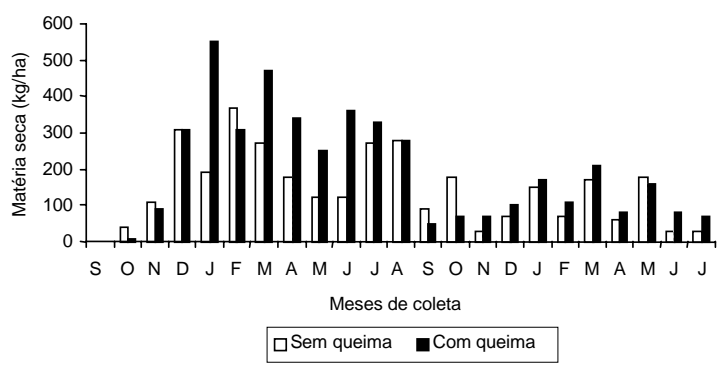

FIG. 3. Variação mensal de biomassa aérea de Axonopus purpusii nos tratamentos sem queima (SQ) e com queima anual (CQ) em setembro/95 e em agosto/96, em campo de Elyonurus muticus no Pantanal, no período de outubro/95 a julho/97.



FIG. 4. Variação mensal de biomassa aérea de Mesosetum chaseae nos tratamentos sem queima (SQ) e com queima anual (CQ) em setembro/95 e em agosto/96, em campo de Elyonurus muticus no Pantanal, no período de outubro/95 a julho/97.

Pesq. agropec. bras., Brasília, v.35, n.8, p.1501-1507, ago. 2000 
perada (Penfound \& Kelting, 1950; Kucera \& Ehrenreich, 1962).

A redução da produção primária do primeiro para o segundo período de avaliação, na área $S Q$, pode ser constatada pela pequena variação verificada na BV presente nesta área (Fig. 2); nota-se que a partir de fev./96 os valores permaneceram entre $3.500 \mathrm{~kg} / \mathrm{ha}$ e $4.500 \mathrm{~kg} / \mathrm{ha}$, o que sugere que na ausência de animais esta área tenha atingido o seu limite de produção. Blydenstein (1963) verificou que nos llanos venezuelanos as áreas protegidas do fogo também apresentavam, depois de algum tempo, uma redução na produção primária líquida. Segundo Meirelles (1981), a proteção de campos contra o fogo reduz a produtividade, e esta redução tem sido atribuída ao efeito de proteção térmica do folhedo, à menor taxa na reciclagem de nutrientes e à presença de toxinas no folhedo, entre outros.

Na região temperada, para Kucera \& Ehrenreich (1962), o incremento da produção primária após o fogo seria auxiliado pela elevação da temperatura do solo e redução de sua umidade excessiva, proporcionado pela retirada do litter. Rice \& Parenti (1978) constataram que realmente o litter funcionava como um protetor térmico, fazendo com que a temperatura dos solos em áreas protegidas fosse bem menor do que em áreas que sofreram ação do fogo. Essa conclusão talvez não possa ser aplicada nos trópicos, principalmente no Pantanal, cuja temperatura média anual é de $26^{\circ} \mathrm{C}$ (Cadavid Garcia, 1984).

A queima promoveu uma remoção quase total da biomassa aérea, e constatou-se que 30 dias após o fogo a porcentagem de cobertura do solo foi bastante baixa, apresentando valores próximos de 30\% (Fig. 5). Após a primeira queima, nos três meses subseqüentes, a cobertura do solo foi significativamente menor $(\mathrm{P}<0,05)$ na área $C Q$, e após a segunda quei$\mathrm{ma}$, foi significativamente menor $(\mathrm{P}<0,05)$ nos quatro meses subseqüentes. Esses resultados corroboram os apresentados por Fontaneli \& Jacques (1988) e Corrêa \& Aronovich (1979).

Essa baixa cobertura de solo nos primeiros meses após a queima proporciona maior incidência de raios solares na base das plantas, estimulando sua rebrota, mas expõe demasiadamente o solo à ação de chuvas e ventos, e pode aumentar consideravelmente a perda de umidade.

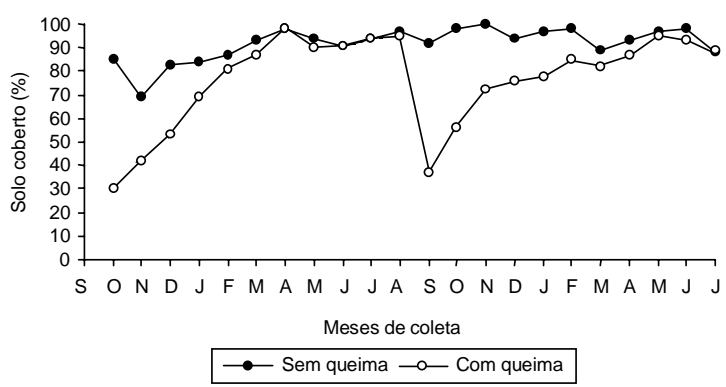

FIG. 5. Variação mensal da cobertura do solo nos tratamentos sem queima (SQ) e com queima anual (CQ) em setembro/95 e em agosto/96, em campo de Elyonurus muticus no Pantanal, no período de outubro/95 a julho/97.

\section{CONCLUSÕES}

1. A queima anual do campo de caronal reduz a biomassa aérea acumulada, em, aproximadamente, $36 \%$ e $50 \%$, no primeiro e segundo ano, respectivamente.

2. A queima condiciona maior incremento mensal de biomassa viva, tornando superior a produção primária líquida da parte aérea do estrato herbáceo.

3. A cobertura do solo reduz-se consideravelmente com a queima, e leva de quatro a seis meses para restabelecer o porcentual da área sem queima.

\section{REFERÊNCIAS}

AMISSAH, J.B.; HALLS, J.B.; SWAINE, M.D.; ATTAKORAH, J.Y. A re-assessment of a fire protection experiment in north-eastern Ghana Savanna. Journal of Applied Ecology, Oxford, v.17, p.85-99, 1980.

BATMANIAN, G.J. Efeitos do fogo sobre a produção primária e a acumulação de nutrientes do estrato rasteiro de um cerrado. Brasília : Universidade de Brasília, 1983. 78p. Dissertação de Mestrado.

BLYDENSTEIN, J. Cambios en la vegetación después de la protección contra el fuego. Parte I. El aumento anual en material vegetal en varios sitios quemados y no quemados en la Estación Biológica. Boletin de la Sociedad Venezolana de Ciencias Naturales, Caracas, v.103, p.233-238, 1963.

BRÂNCIO, P.A.; NASCIMENTO JÚNIOR, D.; REGAZZI, A.J.; MORAES, E.A.; LEITE, G.G. 
Avaliação de pastagem nativa dos cerrados submetida à queima anual. 1. Composição botânica da dieta de bovinos. Revista Brasileira de Zootecnia, Viçosa, v. 26, n.3, p.429-437, 1997.

CADAVID GARCÍA, E.A. O clima no Pantanal MatoGrossense. Corumbá : Embrapa-CPAP, 1984. 39p. (Embrapa-CPAP. Circular Técnica, 14).

CASTILHOS, Z.M. de S.; JACQUES, A.V.A. Produção e qualidade de uma pastagem natural submetida a tratamentos de introdução de trevo vesiculoso cv. Yuchi (Trifolium vesiculosum Savi), ceifa e queima. Anuário Técnico do Instituto de Pesquisas Zootécnicas Francisco Osório, Porto Alegre, v.11, p.103-144, 1984.

CAVALCANTI, L.H. Efeito das cinzas resultantes da queimada sobre a produtividade do estrato herbáceo subarbustivo de Emas (Pirassununga-SP). São Paulo : USP, 1978. 219p. Tese de Doutorado.

CESAR, H.L. Efeitos da queima e corte sobre a vegetação de um campo sujo na fazenda Água Limpa, Distrito Federal. Brasília : Universidade de Brasília, 1980. 59p. Dissertação de Mestrado.

COMASTRI FILHO, J.A. Pastagens nativas e cultivadas no Pantanal Mato-Grossense. Corumbá : Embrapa-UEPAE Corumbá, 1984. 48p. (EmbrapaUEPAE Corumbá. Circular Técnica, 13).

CORRÊA, A.N.S.; ARONOVICH, S. Influência da queima periódica sobre a vegetação e sobre a fertilidade dos terrenos de pastagens. Revista da Sociedade Brasileira de Zootecnia, Viçosa, v.8, n.2, p.332347, 1979.

COUTINHO, L.M. Contribuição ao conhecimento do papel ecológico das queimadas na floração de espécies do cerrado. São Paulo : USP, 1976. 173p. Tese de Livre-Docência.

COUTINHO, L.M.; DE VUONO, Y.S.; LOUSA, J.S. Aspectos ecológicos do fogo no cerrado. IV. A época da queimada e a produtividade primária líquida epigéia do estrato herbáceo subarbustivo. Revista Brasileira de Botânica, São Paulo, v.5, p.37-41, 1982.

DE BANO, L.F.; CONRAD, C.E. The effect of fire on nutrient in Chaparral ecosystem. Ecology, Washington, v.59, p.489-497, 1978.

FONTANELI, R.S.; JACQUES, A.V.A. Melhoramento de pastagem natural: ceifa, queima, diferimento e adubação. Revista da Sociedade Brasileira de Zootecnia, Viçosa, v.17, n.2, p.180-194, 1988.

KUCERA, D.L.; DAHLMAN, R.C.; KOELLING, R. Total net productivity and turnover on energy basis for tall grass prairie. Ecology, Washington, v.48, p.536-541, 1967.

KUCERA, D.L.; EHRENREICH, J.H. Some effects of annual burning of Central Missouri Prairie. Ecology, Washington, v.43, p.334-336, 1962.

MEIRELLES, M.L. Produção primária e suas relações com os fatores ambientais em pastagem artificial e campo sujo de cerrado, queimado e natural. Brasília : Universidade de Brasília, 1981. 76p. Dissertação de Mestrado.

NEIVA, J.N.M. Crescimento e valor nutritivo de pastagens nativas submetidas ou não ao tratamento de queima. Lavras : ESAL, 1990. 97p. Dissertação de Mestrado.

PENFOUND, W.T.; KELTING, R.W. Some effects of winter burning on a moderately grazed pasture. Ecology, Washington, v.31, n.4, p.554-560, 1950.

POTT, A. Pastagens das sub-regiões dos Paiaguás e da Nhecolândia do Pantanal Mato-Grossense. Corumbá : Embrapa-UEPAE Corumbá, 1982. 49p. (Embrapa-UEPAE Corumbá. Circular Técnica, 10).

POTT, A. Pastagens no Pantanal. Corumbá : EmbrapaCPAP, 1988. 58p. (Embrapa-CPAP. Documentos, 7).

POTT, E.B.; CATTO, J.B.; BRUM, P.A.R. Períodos críticos de alimentação para bovinos em pastagens nativas, no Pantanal Mato-Grossense. Pesquisa Agropecuária Brasileira, Brasília, v.24, n.11, p.1427-1432, nov. 1989.

RICE, E.L.; PARENTI, R.L. Causes of decreases in undisturbed tall grass prairie. American Journal of Botany, Columbus, v.65, n.10, p.1091-1097, 1978.

SAN JOSÉ, J.J.; MEDINA, E. Effect of fire on organic matter production and water balance in a tropical savanna. In: GOLLEY, F.B.; MEDINA, E. (Ed.). Tropical ecological systems: trends in terrestrial and aquatic research. New York : Springer, 1975. p.251-264. (Ecological Studies Analysis and Synthesis, 11).

SAS INSTITUTE (Cary, Estados Unidos). SAS/STAT user's guide. 4.ed. Cary, 1989. v.2.

SINGH, J.S.; LAUENROTH, W.K.; STEINHORST, R.K. Review and assessment of various techniques for estimating net aerial primary production in Grasslands from harvest data. Botanical Review, New York, v.41, n.2, p.181-232, 1975.

WIEGERT, R.G.; EVANS, F.C. Primary production and the disappearance of dead vegetation on an old field in Southeastern Michigan. Ecology, Washington, v.45, n.1, p. 49-61, 1964.

Pesq. agropec. bras., Brasília, v.35, n.8, p.1501-1507, ago. 2000 